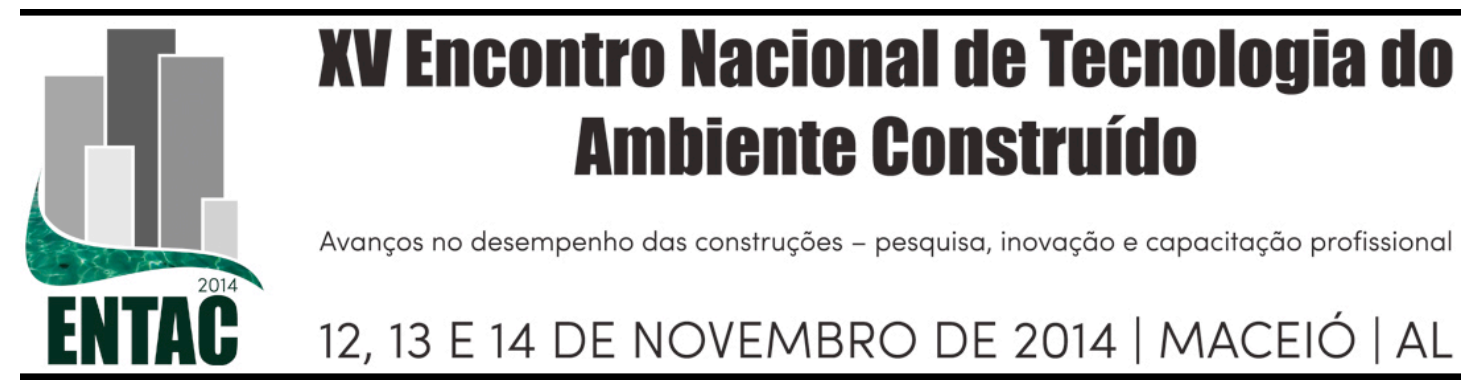

\title{
AVALIAÇÃO DOS LIMITES DAS PROPRIEDADES TÉRMICAS DOS FECHAMENTOS OPACOS DA NBR 15220-3, PARA HABITAÇÕES DE INTERESSE SOCIAL, DA ZONA BIOCLIMÁTICA 2.
}

\author{
OLIVEIRA, Liader [1]; SILVA, Antônio César S. B.[2]; PINTO, Mônica Martins \\ [3] \\ (1) UFPEL, liader@globo.com (2) UFPEL, acsbs@uol.com.br (3) UFPEL, \\ monicamartinspinto@outlook.com
}

\begin{abstract}
RESUMO
O presente trabalho teve por objetivo fazer uma análise dos valores recomendados pela NBR 15220 parte 3, para habitações de interesse social, e considerados como limites de transmitância térmica, atraso térmico e fator de calor solar, para fechamentos verticais, para a zona bioclimática 2 brasileira. Para isto, primeiramente definiu-se as características construtivas da habitação a ser simulada no trabalho, de forma a que atendesse às especificações mínimas propostas pelo programa Minha Casa Minha Vida. Os fechamentos opacos, paredes e cobertura, do caso-base, foram definidos a partir dos limites das propriedades térmicas indicadas pela NBR 15220-3, para a zona bioclimática 2. Os resultados obtidos com o caso-base estabeleceram os referenciais de conforto térmico com os quais as diversas configurações de envelope simuladas posteriormente foram comparadas, e possibilitaram verificar a pertinência das recomendações estabelecidas na norma. A análise dos resultados indicou que não se justificam os limites estabelecidos pela NBR 15220-3 para as variáveis de atraso térmico e fator de calor solar, quando avaliados pelos índices de conforto térmico obtidos com as simulações. Foi possível verificar que, tanto o aumento do atraso térmico quanto da absortância solar são benéficos para o conforto térmico no interior da edificação ao longo do ano na zona bioclimática 2, onde predominam as situações de desconforto no inverno.
\end{abstract}

Palavras-chave: NBR 15220; transmitância térmica, atraso térmico.

\begin{abstract}
The present study aimed to analyze the values recommended by the NBR 15220 - part 3 and considered as limits of thermal transmittance, thermal lag factor and solar heat for vertical components to the bioclimatic zone 2 brazilian. So, at the first moment the construction characteristics of the housing to be simulated in this work were definid, so that they would meet the minimum specifications proposed by the Minha Casa Minha Vida Federal Government Program. The opaque closures walls and roof, of the base case, were defined from the limits set by the thermal properties of NBR 15220-3, for bioclimatic zone 2. The results obtained with the simulation of base case established thermal comfort, with which various configurations of the envelope were simulated and subsequently compared, making possible to verify the relevance of the recommendations set forth in the standard. The results indicated that the limits established by NBR 15220-3 are not justified for thermal lag factor and solar heat variables, when evaluated by thermal comfort indices obtained by simulation. It was possible to verify that both the thermal lag as the solar absorptance increasing are beneficial for the indoor thermal comfort over the years climatic zone 2, where the situations of discomfort in winter are predominant.
\end{abstract}

.Keywords: NBR 15220; thermal transmittance, thermal lag. 


\section{INTRODUÇÃO}

Segundo dados do Programa Nacional de Amostra por Domicílios (PNAD) de 2009, para zerarmos o déficit habitacional nacional precisaríamos construir quase 5,6 milhões de moradias. O Programa de Aceleração do Crescimento (PAC), através do Programa Minha Casa Minha Vida, disponibiliza elevados recursos financeiros para a redução deste déficit que, porém, não garantem a qualidade da moradia. $O$ reflexo da má qualidade da construção é que, além da precariedade das condições de conforto no interior das edificações, há um gasto excessivo de energia para que, artificialmente, estas condições sejam atendidas (Almeida e Cabús, 2005). Este conforto artificial, porém, tem um custo elevado no orçamento mensal das famílias de menor renda.

A preocupação crescente com o nível de conforto dos usuários e, principalmente, com o consumo desnecessário de energia de edificações mal projetadas ou construídas com materiais não adequados conduziu a uma recente normatização sobre o tema. A Associação Brasileira de Normas Técnicas (ABNT) publicou, nos últimos anos, duas normas: a NBR 15220 - Desempenho Térmico de Edificações - em 2005 e a NBR 15575 - Desempenho de Edifícios Habitacionais de até Cinco Pavimentos - em 2008.

A NBR 15220, em sua parte 3, define recomendações quanto ao desempenho térmico de habitações unifamiliares de interesse social, indicando as diretrizes construtivas e as estratégias bioclimáticas mais adequadas para diversas zonas bioclimáticas, porém não tem caráter compulsório. Além disso muitas das prescrições contidas na norma, principalmente em relação as características físicas dos fechamentos (transmitância térmica, atraso térmico e fator de calor solar), tem sido contestadas em trabalhos de pesquisadores da área.

Menezes (2006) realizou medições in loco de temperatura e umidade no interior e no exterior de edificações de interesse social na cidade de Passo Fundo, zona bioclimática 2, e também modelou as mesmas edificações através do programa EnergyPlus. Os relatórios do processo de simulação computacional foram confrontados com os dados medidos e foi constatado que o período de desconforto térmico é muito maior devido ao frio do que devido ao calor, sendo feita a indicação de um aumento da inércia térmica da edificação, juntamente com outras estratégias de condicionamento térmico passivo, para melhorar o conforto térmico da edificação.

Matos (2007) observou, através de um processo de simulação computacional em habitações com o uso de ventilação natural, que a limitação do atraso térmico previsto na norma não se justificaria, em função de que todas as paredes com transmitância dentro dos limites estabelecidos apresentam semelhança nos resultados de graus-hora para a zona bioclimática 3 .

A própria NBR 15575, posterior à NBR 15220, já utiliza alguns parâmetros diferentes para avaliação simplificada das edificações. A NBR 15575 utiliza a capacidade térmica e não o atraso térmico como limitador, mesmo critério do Regulamento Técnico da Qualidade para o Nível de Eficiência Energética de Edificações Residenciais, o RTQ-R (2010), que o usa como pré-requisito.

\section{OBJETIVO}

Avaliar, através de simulação computacional com o programa Designbuilder as prescrições da NBR 15220 - parte 3, quanto às características térmicas - transmitância térmica, atraso térmico e fator de calor solar - dos fechamentos opacos verticais, propondo uma correlação entre essas variáveis a partir da análise das condições de 
conforto térmico de uma habitação de interesse social, para a zona bioclimática 2 brasileira.

\section{MÉTODO}

A metodologia utilizada para atingir-se os resultados finais se desenvolveu em quatro etapas distintas, discriminadas a seguir:

\subsection{Definição do Caso-Base}

\subsubsection{Tipologia e Geometria da Edificação}

Para determinação da tipologia da habitação a ser estudada verificou-se as especificações mínimas que constam no site do Ministério das Cidades para o programa Minha Casa Minha Vida "2" e o código de obras do município de Pelotas, zona bioclimática 2, buscando uma habitação que represente a tendência atual da construção civil no país. Com base nessas premissas foi desenvolvido um projeto de habitação que atendesse a todas as especificações. Ela possui dois dormitórios, sala e cozinha conjugadas e banheiro, totalizando $40,8 \mathrm{~m}^{2}$, conforme Figura 1.

\section{Figura 1 - Planta baixa da edificação (caso-base)}
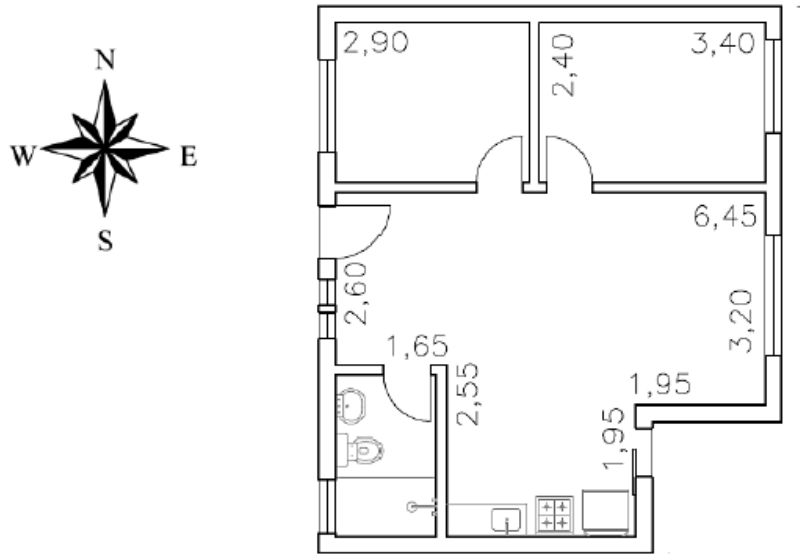

\subsubsection{Padrões de Ocupação e Utilização}

Quanto à ocupação dos ambientes foi utilizado o padrão descrito no Regulamento Técnico da Qualidade para o Nível de Eficiência Energética de Edificações Residenciais (RTQ-R, 2010), que também serviu de base para definição da taxa metabólica das atividades desempenhadas em cada ambiente, padrão de uso e densidade de potência da iluminação e cargas internas de equipamentos.

\subsubsection{Definição da Temperatura do Solo}

Em relação à temperatura do solo foi utilizado o programa $S L A B$, do EnergyPlus, para calcular a temperatura média do solo para cada mês do ano, com base nos valores médios de temperaturas internas e externas da edificação para o clima escolhido, levando em conta sua geometria, elementos construtivos e padrões de uso e ocupação. 


\subsubsection{Fechamentos Verticais e Horizontais}

Para a caracterização dos materiais e elementos construtivos que comporão os fechamentos opacos, inicialmente, com base na NBR 15220-3, foram definidas as propriedades térmicas de paredes externas e cobertura, em função do zoneamento bioclimático. Para a zona bioclimática 2 as paredes devem ser leves e a cobertura leve e isolada, conforme tabela C.2. do anexo C da NBR 15220-3.

\subsubsection{Ventilação Natural}

A utilização da ventilação cruzada é a estratégia de condicionamento térmico passivo indicada para a zona bioclimática 2, para a obtenção de conforto térmico no período de verão. Em função disto é fundamental buscarmos parâmetros de entrada, que influenciam na ventilação e infiltração, corretos, para inserção no programa de simulação termo-energética, para não corrermos riscos de analisarmos os dados de saída (conforto térmico) alicerçados em valores de entrada irreais. Os parâmetros indicados pelo Regulamento Técnico da Qualidade para o Nível de Eficiência Energética de Edificações Residenciais (RTQ-R, 2010) foram os utilizados no processo de simulação.

O RTQ-R, em relação à ventilação natural, também estabelece padrões de uso possíveis, como o controle através de padrões horários de abertura e fechamento das aberturas ou estratégias de controle automático, por temperatura ou entalpia. Neste trabalho, a edificação será analisada utilizando o padrão de uso da ventilação natural com controle automático por temperatura. A temperatura de setpoint foi definida em $25^{\circ} \mathrm{C}$, com base em trabalho de Martins et al (2009).

\subsubsection{Operação de Venezianas}

O dispositivo de sombreamento adotado foi uma veneziana horizontal de madeira na cor branca, refletância de 0,8 , cuja condutividade térmica é de $0,23 \mathrm{~W} / \mathrm{m}$.K. Neste trabalho optou-se pela utilização da rotina programada apenas em função do horário, principalmente porque o processo de simulação se torna mais rápido, o que é fundamental pelo elevado número de simulações que serão executadas.

\subsection{Modelagem e Simulação do Caso-Base}

O processo de modelagem e simulação de uma edificação, no programa DesignBuider, deve prever alguns cuidados. Após a definição das características arquitetônicas da edificação e dos principais parâmetros de entrada para utilização pelo programa de simulação computacional, ainda devemos definir o arquivo climático a ser utilizado na simulação e utilizar uma metodologia para construção dos fechamentos opacos.

\subsubsection{Arquivo Climático}

Para o presente trabalho o arquivo climático utilizado será um arquivo representativo da Zona Bioclimática 2: arquivo TMY da cidade de Santa Maria/RS.

\subsubsection{Metodologia para Construção dos Fechamentos Opacos}

A metodologia utilizada pelo programa DesignBuilder para elaborar os componentes construtivos apresenta certas limitações para desenvolver os modelos de materiais e componentes. O programa considera todos os componentes formados por camadas transversais ao fluxo de calor, não permitindo o cálculo de resistências térmicas em paralelo. Desta forma foi utilizado o trabalho de Ordenes et al (2003) que desenvolveu um modelo de construção de um componente equivalente para ser inserido no programa. Neste modelo as espessuras e densidades de massa aparente dos materiais são modificadas, mantendo-se constante a resistência térmica $(\mathrm{Rt})$ e capacidade térmica $(\mathrm{Ct})$ 
entre as superfícies do componente. A metodologia proposta por Ordenes et al (2003) teve que ser adaptada em função de que, no caso-base, não temos a capacidade térmica definida, e sim o atraso térmico.A definição dos fechamentos do caso-base seguiu as indicações da norma para a zona bioclimática 2, em relação as características térmicas limites das vedações externas, conforme tabela C.2. da NBR 15220, parte 3 (ABNT, 2005).

Os valores de espessura e densidade de massa equivalentes, assim como a absortância solar limite para a observância do valor do fator de calor solar, estão representados nas Figuras 2 e 3, para que os fechamentos respeitem exatamente os limites indicados pela NBR 15220 - 3, para a zona bioclimática 2.

Figura 2 - Parede Equivalente ZB2

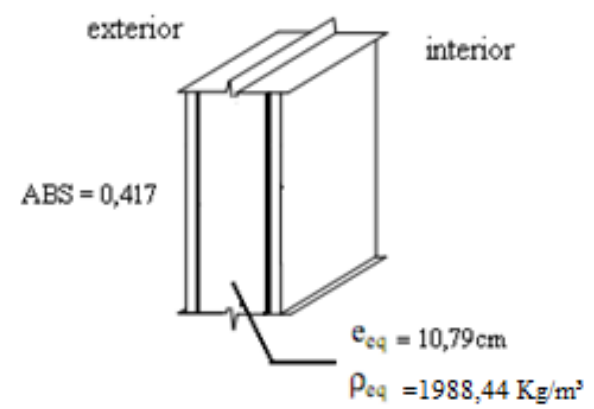

Figura 3 - Cobertura Equivalente ZB2

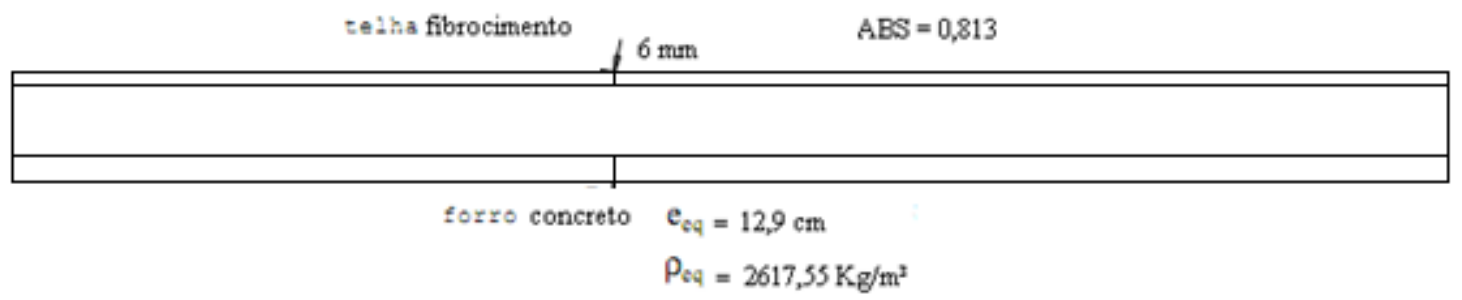

\subsection{Modelagem e Simulação das novas configurações dos Fechamentos Opacos Verticais}

Para a definição das alternativas a serem analisadas a partir do processo de simulação computacional, de forma a atender aos objetivos do trabalho, serão fixados valores de transmitância térmica que abranjam a maioria dos valores de transmitância das paredes e coberturas listadas na NBR $15220-3\left(\right.$ de $1,00 \mathrm{~W} / \mathrm{m}^{2} \mathrm{~K}$ a $\left.5,00 \mathrm{~W} / \mathrm{m}^{2} \mathrm{~K}\right)$ e, a partir daí, serão testados fechamentos com atrasos térmicos de 1 a 11 horas, que também estão contidos na norma. Em relação ao fator de calor solar, todas as configurações serão testadas para as absortâncias de 20\%,50\% e 70\% (Lamberts et al, 2004), de forma a que possamos testar as cores claras, médias e escuras.

\subsubsection{Limitação para inserção de dados no programa computacional}

A densidade de massa específica máxima admitida pelo programa é de $12.000 \mathrm{Kg} / \mathrm{m}^{3}$. Porém a densidade de massa aparente máxima dos materiais que constam na NBR 15220-2, com exceção dos metais, é de $3.000 \mathrm{Kg} / \mathrm{m}^{3}$, para o basalto. Ordenes et al (2003) em seu trabalho, trabalhou com densidade equivalente máxima de $3.836 \mathrm{Kg} / \mathrm{m}^{3}$ para paredes de material cerâmico (tijolos furados). Em função disso limitaremos a densidade equivalente máxima a este valor, para não fugirmos destes limites já testados. 
fechamentos opacos, permitindo verificar a pertinência dos limites estabelecidos pela norma.

\subsection{Simulação das Novas Configurações de Fechamentos Opacos}

Os resultados de conforto térmico, para a edificação como um todo, em relação aos atrasos térmicos simulados, para as transmitâncias térmicas de 1,00 à $5,00 \mathrm{~W} / \mathrm{m}^{2} \mathrm{~K}$, e absortância solar das paredes de 0,2, estão indicados na Figura 4. Nesta mesma figura já está indicado o referencial de conforto, obtido através da simulação do caso-base.

Figura 4 - Conforto Térmico da HIS para paredes com absortância solar de 0,2

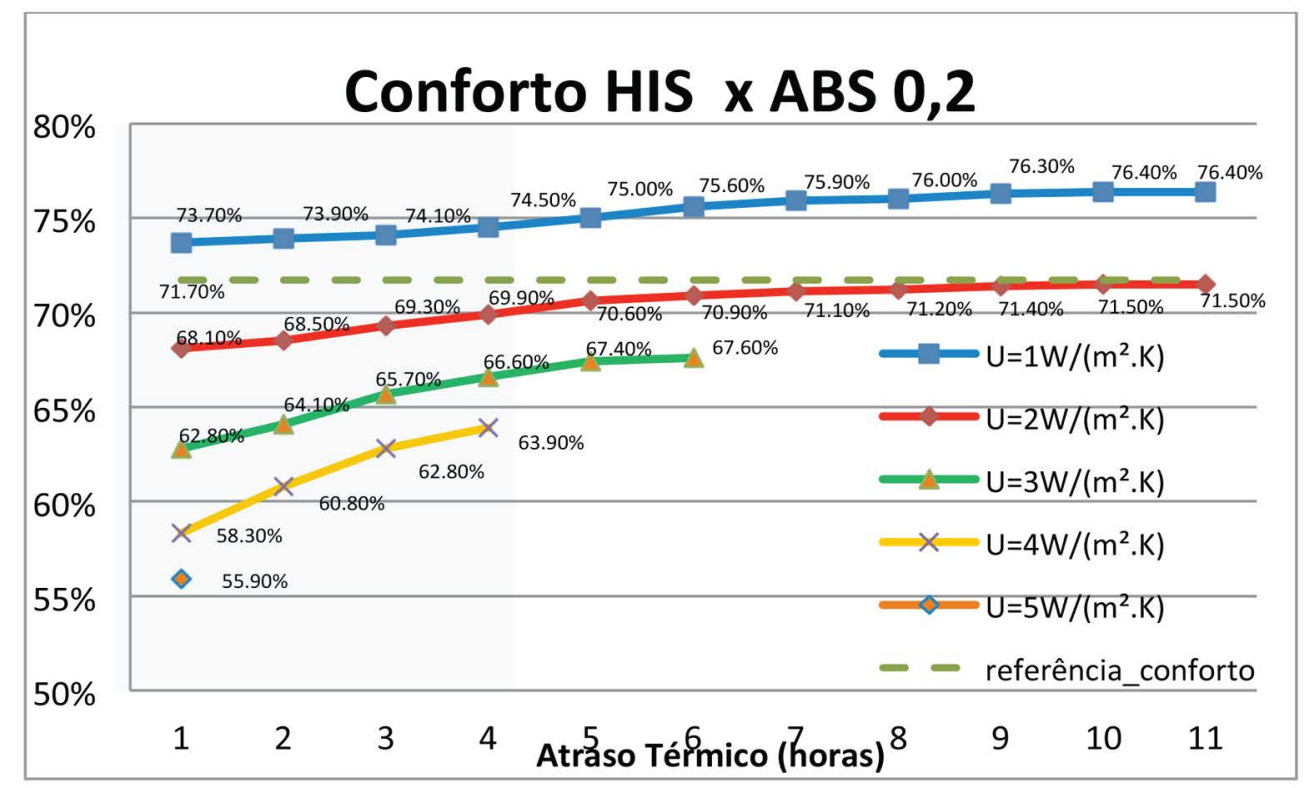

Os resultados indicaram que, para paredes com uma absortância solar de 0,2, apenas aquelas que possuem transmitância térmica de $1,00 \mathrm{~W} / \mathrm{m}^{2} \mathrm{~K}$ conseguem atingir percentuais de conforto térmico acima de $71,70 \%$, referência de conforto estabelecida pelos resultados obtidos a partir da simulação do caso-base. Além disso também podemos observar que o aumento do atraso térmico elevam o conforto no interior da edificação, contrariando as expectativas geradas pela análise das recomendações da NBR 15220-3, que indicam um valor máximo para o atraso térmico dos fechamentos opacos verticais de 4,3 horas.

Outra constatação importante é que, fechamentos de transmitância térmica de 2,00 e $3,00 \mathrm{~W} / \mathrm{m}^{2} \mathrm{~K}$, com absortância de 0,2 , possuem fator de calor solar de 1,6 e 2,4\%, respectivamente, e se encontram dentro dos valores aceitáveis pela norma, de menos de $5 \%$. Estes fechamentos, com atraso térmico até 4,3 horas, que é o valor estabelecido como máximo pela NBR 15220-3, estão dentro dos limites indicados para habitações na zona bioclimática 2 mas, como podemos observar pelos resultados, não atingem os padrões de referência estabelecidos pela simulação do caso-base.

Os resultados de conforto térmico obtidos para a edificação como um todo, em relação aos atrasos térmicos simulados, para as transmitâncias térmicas de 1,00 à $5,00 \mathrm{~W} / \mathrm{m}^{2} \mathrm{~K}$, e absortância solar das paredes de 0,5 e 0,7, estão indicados nas Figuras 5 e 6. 
Figura 5 - Conforto Térmico da HIS para paredes com absortância solar de 0,5

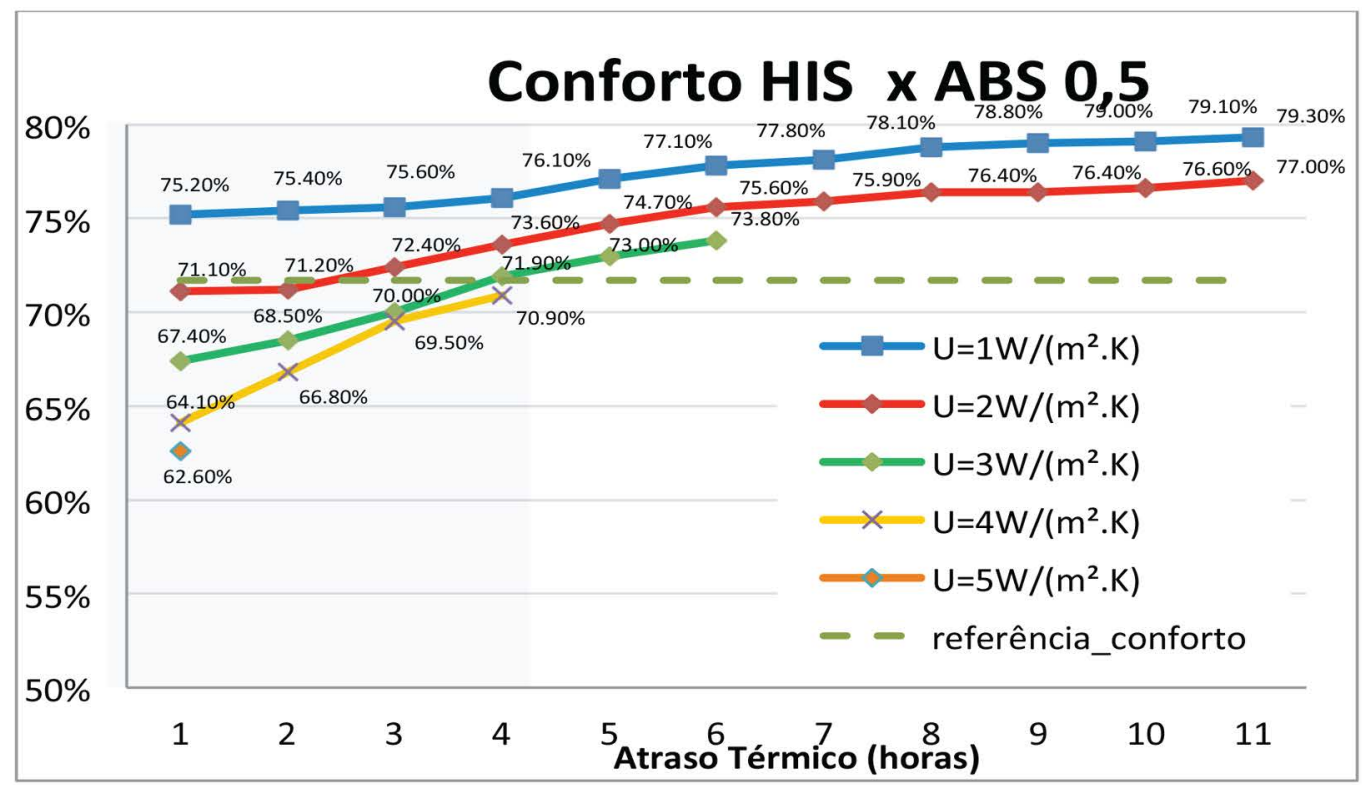

Figura 6 - Conforto Térmico da HIS para paredes com absortância solar de 0,7

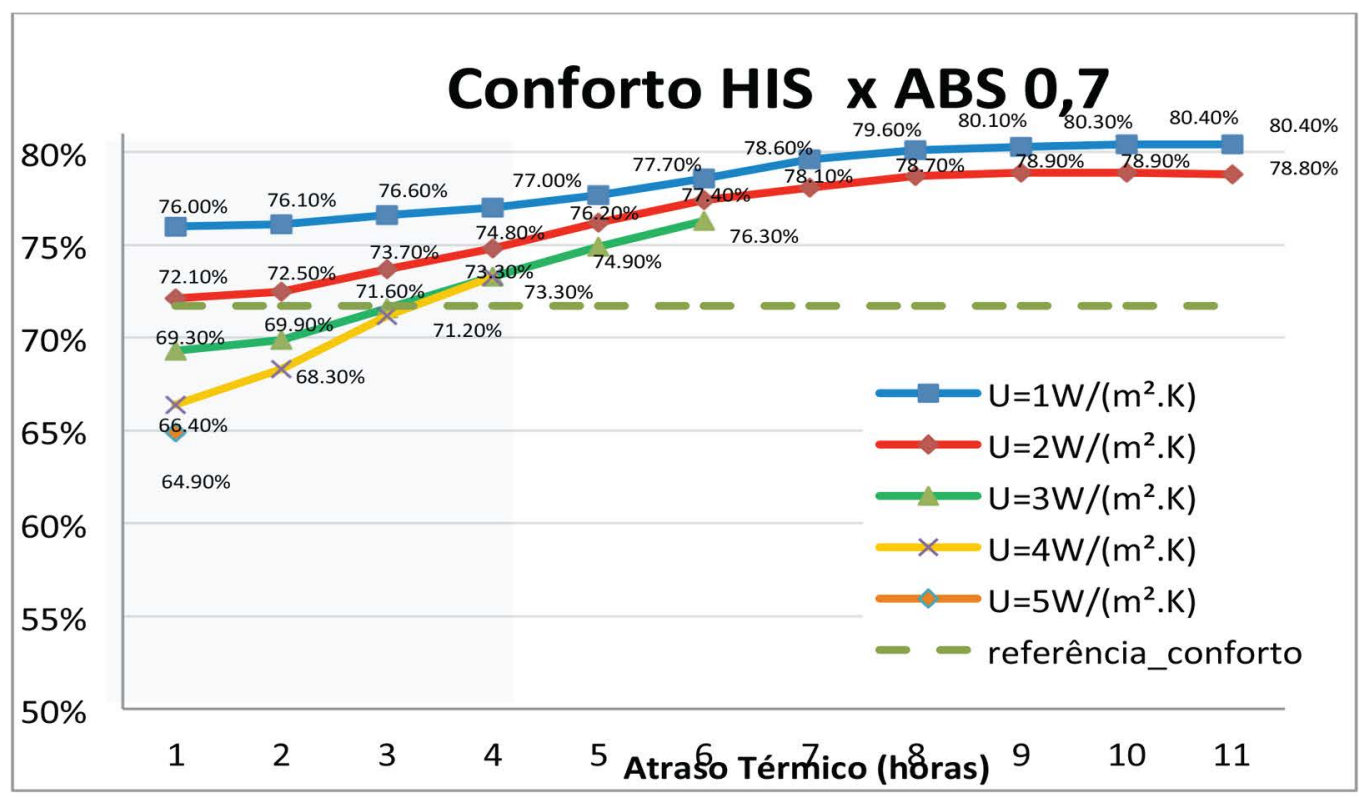

Os resultados indicaram que, para paredes com uma absortância solar de 0,5 , apenas aquelas que possuem transmitância térmica de $1,00 \mathrm{~W} / \mathrm{m}^{2} \mathrm{~K}$ conseguem atingir percentuais de conforto térmico acima da referência de conforto estabelecida pela simulação do caso-base, para todos os valores de atraso térmico.

Para paredes com transmitância de $2,00 \mathrm{~W} / \mathrm{m}^{2} \mathrm{~K}$ o valor de referência é ultrapassado para um atraso térmico situado entre duas e três horas. E para fechamentos com transmitância térmica de $3,00 \mathrm{~W} / \mathrm{m}^{2} \mathrm{~K}$ este limite é ultrapassado com um atraso térmico de, aproximadamente, quatro horas.

Já para paredes com uma absortância solar de 0,7 apenas aquelas que possuem transmitância térmica de 1,00 e $2,00 \mathrm{~W} / \mathrm{m}^{2} \mathrm{~K}$, conseguiram atingir percentuais de conforto térmico acima da referência de conforto estabelecida pela simulação do caso- 
As configurações que serão analisadas neste trabalho, em função desta limitação, estão indicadas na Tabela 1.

Tabela 1 - Configurações de Simulação Analisadas

\begin{tabular}{|c|c|c|c|c|c|c|c|c|c|c|c|c|}
\hline \multirow{6}{*}{ PAREDES } & $\begin{array}{r}\phi(\mathrm{hs}) \\
U\left(\mathrm{~W} / \mathrm{m}^{2} \mathrm{~K}\right) \\
\end{array}$ & 1 & 2 & 3 & 4 & 5 & 6 & 7 & 8 & 9 & 10 & 11 \\
\hline & 1 & $\mathrm{C} 1$ & $\mathrm{C} 6$ & C11 & C16 & $\mathrm{C} 21$ & $\mathrm{C} 26$ & C31 & $\mathrm{C} 36$ & C41 & C46 & C51 \\
\hline & 2 & $\mathrm{C} 2$ & $\mathrm{C} 7$ & $\mathrm{C} 12$ & $\mathrm{C} 17$ & $\mathrm{C} 22$ & $\mathrm{C} 27$ & C32 & C37 & C42 & C47 & C52 \\
\hline & 3 & $\mathrm{C} 3$ & $\mathrm{C} 8$ & $\mathrm{C} 13$ & C18 & $\mathrm{C} 23$ & $\mathrm{C} 28$ & C33 & $\mathrm{C} 38$ & $\mathrm{C} 43$ & $\mathrm{C} 48$ & $\mathrm{C} 53$ \\
\hline & 4 & $\mathrm{C} 4$ & C9 & C14 & $\mathrm{C} 19$ & $\mathrm{C} 24$ & $\mathrm{C} 29$ & C34 & C39 & C44 & C49 & C54 \\
\hline & 5 & C5 & $\mathrm{C} 10$ & C15 & C20 & $\mathrm{C} 25$ & С 30 & C35 & C40 & C45 & C50 & C55 \\
\hline
\end{tabular}

\subsection{Tratamento e Análise dos Dados de Saída}

O tratamento dos dados será realizado através de uma análise comparativa dos desempenhos de cada modelo com base na porcentagem de horas de conforto, considerando a zona de conforto adaptada de Givoni (1992), que deram sustentação para a elaboração das recomendações e estratégias da NBR 15220 - parte 3.. Para isso foi utilizado o programa computacional Analysis Bio, inserindo os valores horários de temperatura e umidade relativa do ar obtida em cada modelo simulado, para o ano inteiro. Os resultados serão analisados para toda a edificação, durante as $24 \mathrm{hs}$ do dia.

\section{ANÁLISE DOS RESULTADOS}

Primeiramente são apresentados os resultados referentes a análise do caso-base. Após a avaliação do caso base, inicia-se a apresentação dos resultados das alternativas simuladas com a mudança da configuração dos fechamentos verticais.

\subsection{Resultados do Caso-Base}

Os resultados obtidos para o caso-base, que possuem os fechamentos opacos modelados com os valores limites das propriedades térmicas referidos na NBR 15220-3 (ABNT, 2005), para a edificação como um todo, estão indicados na Tabela 2.

Tabela 2 - Conforto Térmico do Caso-Base

\begin{tabular}{|c|c|c|c|c|c|}
\hline \multirow{2}{*}{\multicolumn{2}{|c|}{ 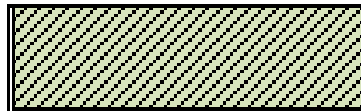 }} & \multirow{2}{*}{ CONFORTO } & \multicolumn{3}{|c|}{ DESCONFORTO } \\
\hline & & & TOTAL & FRIO & CALOR \\
\hline$\alpha=41,8 \%$ & TOTAL & $71,70 \%$ & $28,30 \%$ & $14,60 \%$ & $13,70 \%$ \\
\hline
\end{tabular}

\subsubsection{Padrões de Conforto}

A simulação do caso-base e a quantificação dos valores de conforto térmico obtidos nos permitem indicar os padrões de conforto estabelecidos a partir da modelagem da edificação com os limites das propriedades térmicas dos fechamentos, estabelecidos pela NBR 15220-3. Estes valores, indicados na Tabelas 2, serão comparados com os resultados obtidos a partir da simulação da habitação com outras propriedades dos 
base, para todos os valores de atraso térmico. Cabe salientar que, apesar de não ser indicada pela NBR 15220-3, por ter seu fator de calor solar acima do limite estabelecido de $5 \%$, a parede de transmitância térmica de $2,00 \mathrm{~W} / \mathrm{m}^{2} \mathrm{~K}$ e absortância solar de 0,7 $(\mathrm{FCS}=5,6 \%)$ obteve, para qualquer valor de atraso térmico, níveis de conforto superiores ao caso-base.

A análise das Figuras 4, 5 e 6 nos indicam a grande quantidade de alternativas simuladas que proporcionam conforto térmico maior que a referência estabelecida pelos limites da própria norma, mas não são indicadas pela mesma. Além de várias outras alternativas que, indicadas pela norma, não atingem o valor de referência.

\section{CONCLUSÕES}

Este trabalho teve, como objetivo geral, avaliar as prescrições da NBR 15220 - parte 3 quanto as características dos fechamentos opacos verticais, buscando propor uma correlação entre as variáveis transmitância, atraso térmico e fator de calor solar para a zona bioclimática 2 brasileira.

As recomendações da NBR 15220-3, principalmente as que limitam o valor do atraso térmico de paredes em 4,3 horas, para a zona bioclimática 2, impedem a obtenção de melhores índices de conforto térmico na edificação. Os resultados obtidos através do processo de simulação computacional apontam que o aumento do atraso térmico dos fechamentos opacos é benéfico para a elevação destes índices.

Estes mesmos resultados indicaram que valores de absortância solar mais elevados produzem um percentual maior de conforto térmico nas habitações. Assim sendo, a limitação do fator de calor solar prevista na norma também se mostra contrária à obtenção de melhores índices de conforto na habitação.

Com base nos resultados obtidos nas diversas configurações de fechamentos opacos simulados, e sua comparação com os níveis de referência estabelecidos a partir da simulação do caso-base, foram indicados intervalos que pudessem correlacionar às características térmicas dos fechamentos opacos do envelope da edificação, o que está representado na Tabela 3.

Tabela 3 - Indicação dos Valores de Transmitância Térmica, Atraso Térmico e Absortância Solar Admissíveis para a ZB2

\begin{tabular}{|c|c|c|c|}
\hline $\begin{array}{l}\text { Vedaçóes } \\
\text { Externas }\end{array}$ & $\begin{array}{c}\text { Transmitância } \\
\text { Térmica } \mathbf{U} \\
\left(\mathbf{W} /\left(\mathbf{m}^{2} \mathbf{K}\right)\right.\end{array}$ & $\begin{array}{c}\text { Atraso Térmico - } \\
\mathbf{\Phi} \text { (horas) }\end{array}$ & Absortância - $\boldsymbol{\alpha}$ \\
\hline \multirow{2}{*}{ Paredes } & $\mathrm{U} \leq 1,5$ & $\Phi \geq 3$ & $\alpha \geq 0,2$ \\
\cline { 2 - 4 } & $1,5<\mathrm{U} \leq 3,0$ & $\Phi \geq 4$ & $\alpha \geq 0,5$ \\
\hline
\end{tabular}

Mesmo que, neste trabalho, as transmitâncias térmicas simuladas tenham sido apenas números inteiros, procurou-se, na tabela acima, extrapolar os valores para que fosse possível criar faixas de transmitâncias de forma a melhor representar os fechamentos reais. Para isso foram feitas interpolações entre os valores simulados que originaram os resultados que constam na Tabela 3.

Pode-se perceber claramente que as indicações de atraso térmico obtidas no trabalho são diametralmente opostas às recomendações da NBR 15220-3, ao sugerirem atrasos térmicos mínimos, e não máximos, como a norma. 
Em relação ao fator de calor solar os valores indicados também estão em direção oposta às recomendações da norma que, da mesma forma que com o atraso térmico, sugere valores limites máximos. A partir apenas dos três valores de absortância simuladas, representando as cores claras, médias e escuras, verificou-se que valores maiores de absortância solar beneficiam as habitações na obtenção de melhores índices de conforto térmico.

\section{AGRADECIMENTOS}

Ao FINEP, pelo apoio recebido.

\section{REFERÊNCIAS}

ASSOCIAÇÃO BRASILEIRA DE NORMAS TÉCNICAS (ABNT). NBR 15.220: Norma Brasileira de Desempenho Térmico de Edificações, Parte 3: Zoneamento bioclimático brasileiro e diretrizes construtivas para habitações unifamiliares de interesse social. Rio de Janeiro:ABNT, 2005.

NBR 15.575. Norma Brasileira de Desempenho de Edifícios habitacionais até cinco pavimentos. Rio de Janeiro:ABNT, 2012.

ALMEIDA, José E. Castro de; CABÚS, Ricardo C. Conforto Térmico em Apartamentos de um Conjunto Habitacional em Maceió / AL. VIII Encontro Nacional de Conforto no Ambiente Construído. ENCAC. Anais do evento. Maceió, AL, 2005.

GIVONI, B. Confort, climate analysis and building design guidelines. Energy and Building, vol. $18,1992$.

INMETRO - INSTITUTO NACIONAL DE METROLOGIA, NORMALIZAÇÃO E QUALIDADE INDUSTRIAL. Regulamento Técnico da Qualidade para o Nível de Eficiência Energética de Edificações Residenciais, RTQ-R. Eletrobrás, 2010.

LAMBERTS, Roberto; DUTRA, Luciano; PEREIRA, Fernando O. R. Eficiência Energética na Arquitetura. 2a edição. São Paulo: ProLivros, 2004.

MARTINS, D. J.; RAU, S. L.; RECKZIEGEL, S.; FERRUGEM, A. P.; SILVA, A. C. S. B. Ensaio sobre a Utilização da Automação de Aberturas na Simulação do Desempenho Térmico de Edificações. X ENCAC. Anais do evento. Natal 2009.

MATOS, Michele. Simulação Computacional do Desempenho Térmico de Residências em Florianópolis Utilizando a Ventilação Natural. Florianópolis: UFSC. Dissertação de Mestrado. Dezembro de 2007.

MENEZES, M. S. Avaliação do desempenho térmico de habitações sociais de Passo Fundo - RS. Dissertação de Mestrado. Faculdade de Engenharia e Arquitetura. Universidade de Passo Fundo. Passo Fundo, 2006.

ORDENES, M.; PEDRINI, A.; GHISI, E.; LAMBERTS, R. Metodologia Utilizada na Elaboração da Biblioteca de Materiais e Componentes Construtivos Brasileiros para Simulações no Visualdoe-3.1. Relatório Interno - Departamento de Engenharia Civil, Universidade Federal de Santa Catarina, Florianópolis, 2003.

PNAD. Pesquisa Nacional por Amostra de Domicílios 2009. Instituto Brasileiro de Geografia e Estatística. Disponível em <http://www.ibge.gov.br>. Acessado em agosto de 2011.

MINISTÉRIO DO DESENVOLVIMENTO, INDÚSTRIA E COMÉRCIO EXTERIOR. Regulamento Técnico da Qualidade para o Nível de Eficiência Energética de Edificações Residenciais, RTQ-R. Eletrobrás, 2010. 